RESEARCH REPORT

\title{
Development of the chronic fatigue syndrome in severely fatigued employees: predictors of outcome in the Maastricht cohort study
}

\author{
Marcus J H Huibers, I Jmert Kant, J André Knottnerus, Gijs Bleijenberg, Gerard M H Swaen, \\ Stanislav V Kasl
}

J Epidemiol Community Health 2004;58:877-882. doi: 10.1136/jech.2003.017939

See end of article for authors' affiliations

.....................

Correspondence to: Dr M J H Huibers, Department of Medical, Clinical and Experimental Psychology, Maastricht University, PO Box 616, 6200 MD Maastricht, Netherlands; m.huibers@ dmkep.unimaas.nl

Accepted for publication 16 February 2004 risk factors of the development of the chronic fatigue syndrome (CFS), the Study objective: To identify risk factors of the development of the chronic fatigue syndrome (CFS), the
persistence or recurrence of fatigue, or recovery from fatigue in a large sample of fatigued employees. Design: Analyses were based on the Maastricht cohort study (MCS), a prospective population based cohort study among more than 12000 employees. Multiple regression models were used to identify predictors of CFS-like caseness (meeting research criteria for CFS), non-CFS fatigue caseness, or no fatigue caseness.

Setting: The working population in the Netherlands.

Participants: 1143 employees with medically unexplained fatigue were followed up prospectively for 44 months.

Main results: At 44 month follow up, $8 \%$ of the employees were CFS-like cases (none of who reported to have received a CFS diagnosis), $40 \%$ were non-CFS fatigue cases, and $52 \%$ were no longer fatigue cases. Factors that predicted CFS-like caseness compared with non-CFS fatigue caseness were high age, exhaustion, female sex, low education, and visits to the general practitioner. Factors that predicted CFSlike caseness compared with no fatigue caseness were fatigue, exhaustion, low education, visits to the GP and occupational physician, and bad self rated health. Factors that predicted non-CFS fatigue caseness compared with no fatigue caseness were fatigue, low self perceived activity, exhaustion, anxious mood, and bad self rated health.

Conclusions: Unexplained fatigue among employees in some instances is a precursor of the development of CFS. The prognostic role of self rated health suggests that prevention and treatment of chronic fatigue should be aimed at changing the perception of health or illness. Less clear is the role of health care seeking or receiving a CFS diagnosis.
$\mathrm{T}$ he chronic fatigue syndrome (CFS) is a condition characterised by persistent medically unexplained fatigue lasting for at least six months, several other unexplained symptoms (for example, sore throat, headache, painful joints) and severe functional impairment. ${ }^{1}$ The cause of CFS is unknown ${ }^{2}$ and most patients do not recover spontaneously. ${ }^{3-8}$

Fatigue can best be understood as a continuum, ranging from mild complaints frequently seen in the community to severe, disabling fatigue like CFS. ${ }^{9}$ From this perspective, the question arises of what the precursors of CFS might be.

In recent years, fatigue in the working population has been the subject of growing interest, not in the least because of its high prevalence $(22 \%)^{10}$ and the adverse consequences of severe fatigue, like reduced performance, sickness absence, ${ }^{11}$ and work disability. ${ }^{12}$

Recently, we studied the relation between unexplained fatigue among employees, burnout, and CFS and found that these conditions shared many characteristics, ${ }^{13}$ with $44 \%$ of the employees with unexplained fatigue meeting the research criteria for CFS. ${ }^{1}$ But can fatigue among employees eventually lead to CFS?

In this study, we seek to identify risk factors of outcome in a large sample of fatigued employees not on sick leave, with "outcome" defined as either the development of CFS, the persistence or recurrence of fatigue, or recovery from fatigue. In line with previous studies of CFS, ${ }^{14-16}$ we hypothesised that severity of fatigue at baseline would be a predictor of fatigue at follow up. In line with a second study, ${ }^{17}$ we hypothesised that factors reflecting the perception of illness (for example, self rated health) would be predictive of the course of fatigue.

\section{METHODS}

\section{Study design and population}

We used prospective data from the Maastricht cohort study on fatigue at work (MCS). In May 1998, 26978 employees from 45 Dutch companies and organisations were invited to participate in the MCS. A total of 12161 employees (45\%) responded by providing informed consent and completing the postal self report questionnaire at baseline. There were no significant differences between respondents and nonrespondents in non-response analyses, except that nonrespondents were less likely to be fatigued or absent from work than respondents. Respondents in the MCS were followed up every four months for three years and eight months (44 months). Further details on the MCS are described elsewhere. ${ }^{18}$

Participants were eligible at baseline of the MCS if they scored 35 or higher on the subscale fatigue severity of the Checklist Individual Strength, ${ }^{19} 20$ a cut off that is indicative of severe fatigue. ${ }^{19} 21$ Fatigued employees at baseline were excluded if they reported a somatic condition that could

Abbreviations: CFS, chronic fatigue syndrome, MCS, Maastricht cohort study 


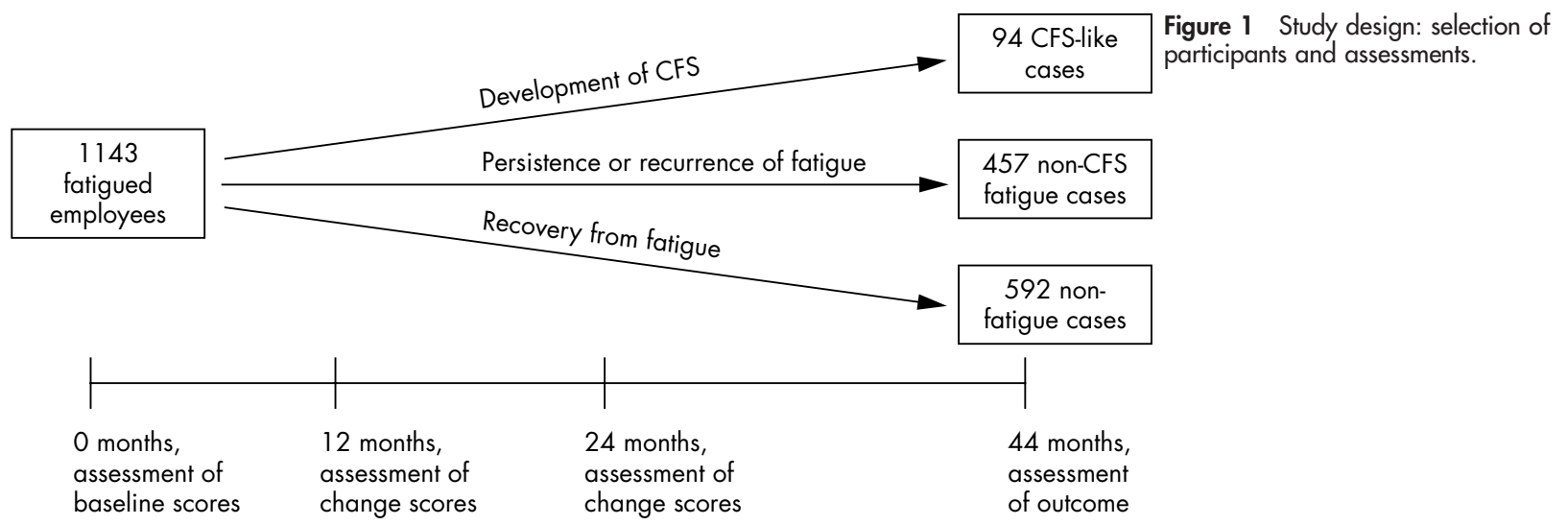

explain fatigue complaints (for example, cerebrovascular accidents, liver dysfunctions, diabetes mellitus, thyroid gland dysfunctions, cancer) or if they were potential CFS-like cases at baseline.

Variables necessary to verify if employees met research criteria for CFS were only available at the final follow up (44 months after baseline). Consequently, we chose to select fatigued employees at baseline who were also available at the 44 month follow up. As CFS criteria could only be fully assessed at the 44 month follow up, we identified potential CFS-like cases at baseline using provisional criteria (see definitions of caseness). Therefore 1143 employees were included in the analyses (fig 1 ).

\section{Predictor variables}

\section{Demographic factors}

Demographic variables included sex, age, and educational level (high, medium, low) and were assessed at baseline.

\section{Fatigue related factors}

Fatigue was assessed with the four subscales of the Checklist Individual Strength (CIS) ${ }^{19}{ }^{20}$ : fatigue severity; concentration; motivation; and self perceived activity. Higher scores on these subscales indicate a higher level of fatigue severity and lower levels of concentration, motivation, and self perceived activity respectively.

Burnout was assessed with the three subscales of the Maslach Burnout Inventory-General Survey (MBI) ${ }^{22}$ : exhaustion; cynicism; and professional efficacy, with higher scores indicating higher levels on these scales.

Need for recovery was assessed with the Need for Recovery scale $^{23} 24$ that indicates the short term effects of a day of work, with a higher score indicating a higher need for recovery.

Participants were asked to indicate whether they felt they had suffered from fatigue complaints in the previous four months (yes or no) and, if so, whether they felt the cause of their fatigue complaints was physical (physical attribution, yes

Table 1 Baseline characteristics of the sample of fatigued employees $(n=1143$ ) classified according to outcome (caseness) at 44 month follow up

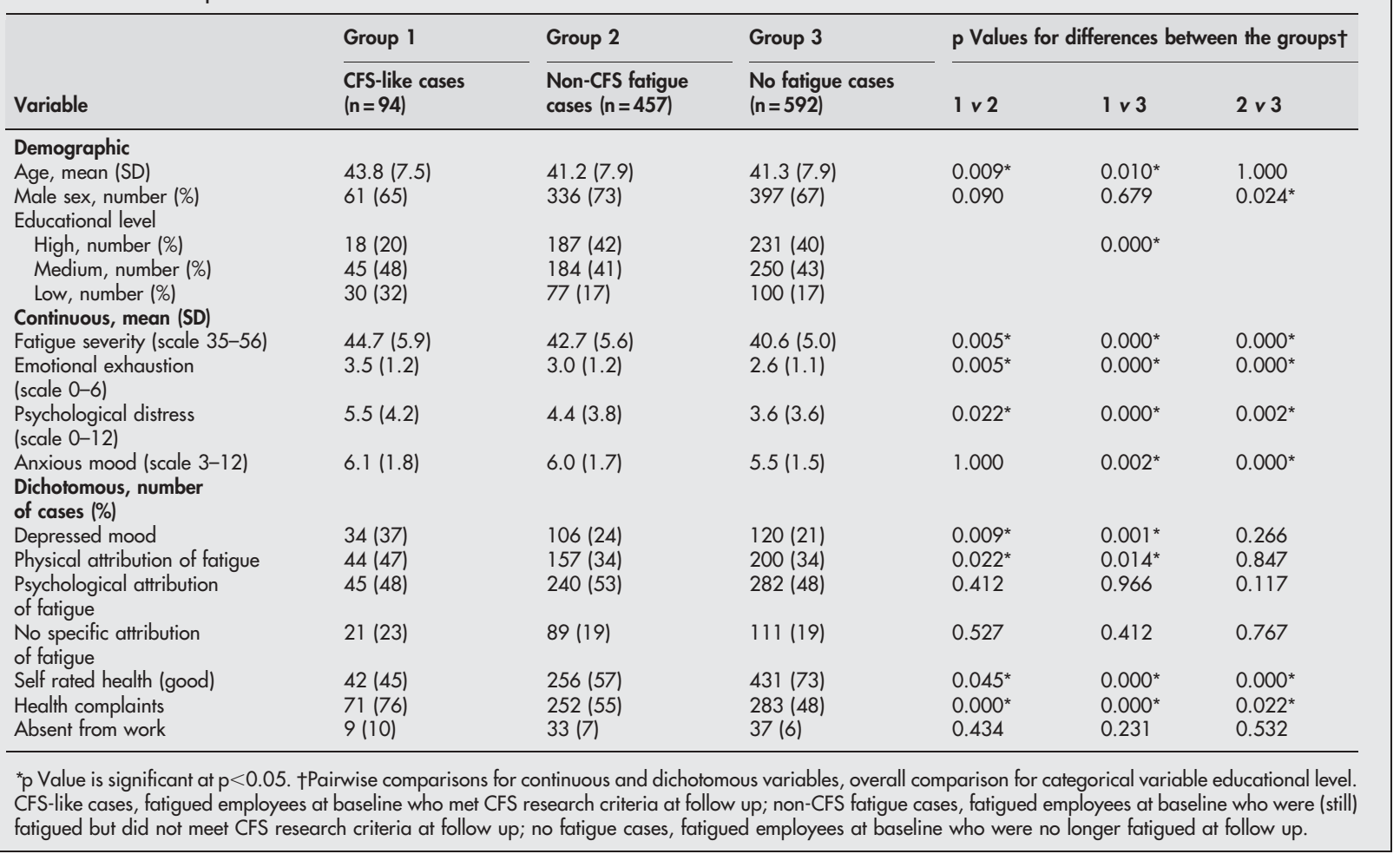


or no) or psychological in nature (psychological attribution, yes or no).

\section{Mental health factors}

Psychological distress was measured with the 12-item version of the General Health Questionnaire (GHQ), ${ }^{25}$ with a higher score indicating a higher level of psychological distress.

Depressed mood was assessed with a single item stating "did you feel down almost every day during the past two weeks, yes or no?"

Anxious mood was measured by adding the scores of three items on anxiety (excessive worrying, compulsive behaviour, compulsive thinking), with a higher score indicating a higher level of anxious mood. Participants were also asked if they had experienced any shocking life events in the past 12 months (yes or no).

\section{Health factors}

Self rated health was assessed with one item from the Short Form Health Survey (SF-36), ${ }^{26}$ which is a widely used measure of general health status. ${ }^{27}$ The original 5 point scale was dichotomised into "good health" and "bad health".

In addition, participants were asked if they: were pregnant (pregnancy, yes or no); had visited their general practitioner (self reported visits to GP) and/or their occupational physician (self reported visits to $O P$ ) in the past four months because of problems at work (yes or no); suffered from health complaints (yes or no); or suffered from sleep disturbances (yes or no).

\section{Miscellaneous factors}

Work status was assessed as self reported sickness absence from work (yes or no). Participants were asked whether their health had impaired them in performing their work (impairment in work, yes or no) and/or their non-work related activities (impairment in activities, yes or no).

\section{Definitions of caseness}

We assessed the outcome in our sample of fatigued employees $(n=1143)$ at the 44 month follow up and classified participants according to three mutually exclusive types of caseness: CFS-like caseness $(\mathrm{n}=94)$, non-CFS fatigue caseness $(n=457)$, and no fatigue caseness $(n=592)$.

Employees were identified as CFS-like cases if they met all of the following research criteria that approximate the Centers for Disease Control and Prevention criteria for $\mathrm{CFS}^{1}$ : a CIS score of 40 or higher, a reported duration of fatigue complaints of six months or more, a SF-36 score on physical functioning of 60 or lower, ${ }^{26}$ and the presence of four or more CFS symptoms. It is emphasised here that CFS-like cases did not necessarily qualify as CFS patients: a CFS diagnosis can only be made by a physician after a sufficient physical examination. However, CFS-like caseness is regarded as a good proxy for CFS diagnosed by a physician. ${ }^{28} 29$

Employees were identified as non-CFS fatigue cases if they scored 35 or higher on the CIS. Fatigue cases who were CFSlike cases as well were excluded from this group. Employees were identified as no fatigue cases if they scored 34 or lower on the CIS.

Potential CFS-like cases at baseline were identified and excluded from analysis based on provisional criteria: a CIS score of 40 or higher at baseline, scoring "yes" on at least one of the two questions on health related impairment at baseline and a reported duration of fatigue complaints of four years or more at 44 month follow up.

In addition, the follow up questionnaire included the following question: "Did you at any time receive a diagnosis of chronic fatigue syndrome or myalgic encephalomyelitis from a qualified physician?"

\section{Statistical analyses}

Group differences in baseline characteristics were tested using one way analysis of variance (continuous variables), the $\chi^{2}$ test (dichotomous variables), and the Kruskal-Wallis test (categorical variables)

Multiple logistic regression models were used to determine separately the associations between predictors and three dichotomies of caseness: CFS-like cases compared with nonCFS fatigue cases $(n=551)$; CFS-like cases compared with no fatigue cases $(n=686)$; and non-CFS fatigue cases compared with no fatigue cases $(n=1049)$. Analyses were performed in two steps. In a first step, baseline predictors that were bivariately associated ( $p$ value $<0.05$ ) with caseness were entered in a multiple logistic model, together with the covariates age, sex, educational level, work status, and pregnancy, and eliminated in a backwards procedure until the model consisted of significant predictors only ( $\mathrm{p}$ value $<0.05)$.

In a second step, prospective change scores of significant predictors were added to the model and the backwards elimination procedure was repeated. Change scores of

Table 2 Risk of CFS-like caseness compared with non-CFS fatigue caseness at 44 month follow up in employees fatigued at baseline $(n=551)$

\begin{tabular}{|c|c|c|}
\hline \multirow[b]{2}{*}{ Predictors } & \multicolumn{2}{|c|}{ Multiple logistic regression models } \\
\hline & $\begin{array}{l}\text { Baseline predictors only* } \\
\text { OR (per SD) }(95 \% \mathrm{CI})\end{array}$ & $\begin{array}{l}\text { Baseline and follow up predictorst } \\
\text { OR (per SD) }(95 \% \text { CI) }\end{array}$ \\
\hline \multicolumn{3}{|l|}{ Continuous } \\
\hline Age & 1.36 (1.08 to 1.84$)$ & 1.36 (1.08 to 1.71$)$ \\
\hline Exhaustion (MBI) & $1.33(1.04$ to 1.67$)$ & 1.52 (1.16 to 2.02 ) \\
\hline - change score t6-t0 & - & $1.36(1.02$ to 1.81$)$ \\
\hline \multicolumn{3}{|l|}{ Dichotomous/categorical } \\
\hline Sex (male =1) & $0.41(0.24$ to 0.70$)$ & $0.36(0.21$ to 0.64$)$ \\
\hline Educational level & & \\
\hline low $v$ high & $3.82(1.92$ to 7.61$)$ & $4.02(1.99$ to 8.11$)$ \\
\hline middle $v$ high & $2.48(1.35$ to 4.51$)$ & $2.48(1.34$ to 4.59$)$ \\
\hline Self reported GP visit (yes $=1$ ) & 1.98 (1.19 to 3.29 ) & $1.87(1.11$ to 3.14$)$ \\
\hline
\end{tabular}

Predictor values are significant odds ratios $(95 \% \mathrm{Cl})$ adjusted for all other predictors in the model. Values of continuous predictors are expressed as OR per SD. +3 , one year assessment; +6 , two year assessment. *Full model included age, sex, educational level, work status, pregnancy, CIS-fatigue, CIS-motivation, need for recovery, MBIexhaustion, impairment in work, impairment in activities, physical attribution of fatigue, psychological distress, depressed mood, life events, visits to GP, visits to occupational physician, self rated health, health complaints, all assessed at baseline. †Full model included age, sex, educational level, MBI-exhaustion (baseline), MBI-exhaustion change score $(+3-10)$, MBl-exhaustion change score ( $(6-+0)$, visits to GP (baseline), visits to GP ( +3$)$, visits to GP ( $(6)$. 
Table 3 Risk of CFS-like caseness compared with no fatigue caseness at 44 month follow up in employees fatigued at baseline $(n=686)$

\begin{tabular}{|c|c|c|}
\hline \multirow[b]{2}{*}{ Predictors } & \multicolumn{2}{|c|}{ Multiple logistic regression models } \\
\hline & $\begin{array}{l}\text { Baseline predictors only* } \\
\text { OR (per SD) }(95 \% \mathrm{CI})\end{array}$ & $\begin{array}{l}\text { Baseline and follow up predictors } \\
\text { OR (per SD) }(95 \%)\end{array}$ \\
\hline \multicolumn{3}{|l|}{ Continuous } \\
\hline Fatigue severity (CIS) & $1.37(1.11$ to 1.86$)$ & $1.86(1.31$ to 2.61$)$ \\
\hline - change score to-t0 & & $1.70(1.11$ to 2.31$)$ \\
\hline Exhaustion (MBI) & $1.66(1.28$ to 2.18$)$ & $1.90(1.33$ to 2.74$)$ \\
\hline - change score t6-t0 & - & 1.55 (1.09 to 2.24$)$ \\
\hline \multirow{2}{*}{\multicolumn{3}{|c|}{ Dichotomous/categorical }} \\
\hline & & \\
\hline low $v$ high & 2.61 (1.29 to 5.24$)$ & $2.29(1.08$ to 4.86$)$ \\
\hline middle $v$ high & $2.38(1.27$ to 4.45$)$ & 2.75 (1.38 to 5.46$)$ \\
\hline Self reported GP visit (yes $=1$ ) & $3.06(1.71$ to 5.50$)$ & - \\
\hline - recent visit to GP (†3) & & 2.01 (1.07 to 3.76$)$ \\
\hline Self reported OP visit (yes $=1$ ) & $0.46(0.22$ to 0.95$)$ & - \\
\hline Self rated health $($ good $=1)$ & $0.56(0.33$ to 0.95$)$ & $0.27(0.14$ to 0.51$)$ \\
\hline - change $+0-+3$ "bad to good" & - & $0.11(0.03$ to 0.35$)$ \\
\hline - change $+3-16$ "good to bad" & & 2.54 (1.14 to 5.66$)$ \\
\hline \multicolumn{3}{|c|}{ 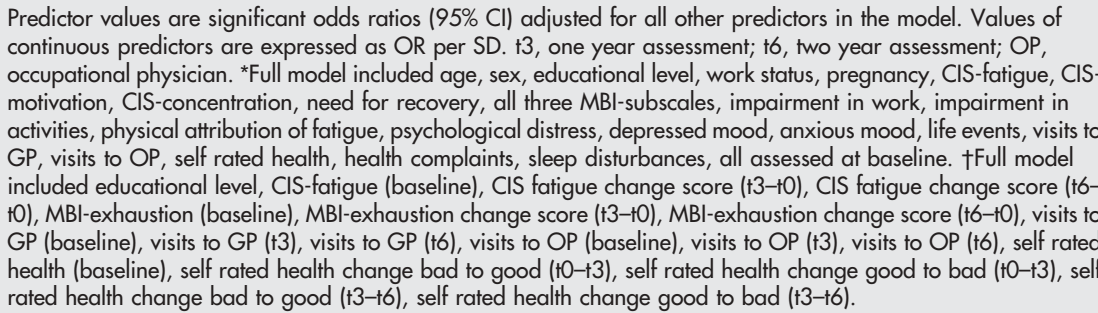 } \\
\hline
\end{tabular}

continuous variables were calculated by subtracting baseline scores from scores at one year (T3) and two years (T6). Change scores of dichotomous variables were also constructed, with the direction of the transition since the previous measurement retained.

\section{RESULTS}

In table 1, baseline characteristics of the 1143 fatigued employees are presented. Three years and eight months after baseline, 94 employees (8\%) were CFS-like cases, 457 employees (40\%) were non-CFS fatigue cases, and 592 employees $(52 \%)$ were no longer fatigue cases. None of the CFS-like cases reported they had received a CFS or myalgic encephalomyelitis diagnosis (not in table 1).

Five baseline factors were found to be predictive of CFSlike caseness at follow up as compared with non-CFS fatigue caseness: high age, high exhaustion, female sex, a low educational level, and a self reported visit to the GP because of problems at work (table 2). When change scores were added in a second step, an increase in exhaustion over time

Table 4 Risk of non-CFS fatigue caseness compared with no fatigue caseness at 44 month follow up in employees fatigued at baseline $(n=1049)$

\begin{tabular}{|c|c|c|}
\hline \multirow[b]{2}{*}{ Predictors } & \multicolumn{2}{|c|}{ Multiple logistic regression models } \\
\hline & $\begin{array}{l}\text { Baseline predictors only* } \\
\text { OR (per SD) }(95 \% \text { CI) }\end{array}$ & $\begin{array}{l}\text { Baseline and follow up predictorst } \\
\text { OR (per SD) }(95 \% \text { CI) }\end{array}$ \\
\hline \multicolumn{3}{|l|}{ Continuous } \\
\hline Fatigue severity (CIS) & 1.24 (1.05 to 1.37$)$ & $1.96(1.61$ to 2.26$)$ \\
\hline - change score $+3-10$ & - & 1.35 (1.23 to 1.65$)$ \\
\hline - change score t6-t0 & - & 2.31 (1.88 to 2.82 ) \\
\hline Self perceived activity (CIS) & 1.18 (1.04 to 1.35 ) & - \\
\hline - change score t6-to & - & $0.78(0.67$ to 0.91$)$ \\
\hline Exhaustion (MBI) & 1.31 (1.13 to 1.53 ) & - \\
\hline Anxious mood & $1.22(1.06$ to 1.40$)$ & 1.29 (1.10 to 1.49$)$ \\
\hline Dichotomous & & \\
\hline $\begin{array}{l}\text { Self rated health (good }=1 \text { ) } \\
\text { - change t0-t3 "bad to good" }\end{array}$ & 0.64 (0.48 to 0.85$)$ & $\begin{array}{l}0.58(0.40 \text { to } 0.84) \\
0.57(0.34 \text { to } 0.97)\end{array}$ \\
\hline
\end{tabular}

Predictor values are significant odds ratios $(95 \% \mathrm{Cl})$ adjusted for all other predictors in the model. Values of continuous predictors are expressed as OR per SD. +3 , one year assessment; 16 , two year assessment. *Full model included age, sex, educational level, work status, pregnancy, all four CIS-subscales, all three MBI-subscales, need for recovery, self rated fatigue complaints, impairment in work, impairment in activities, psychological distress, anxious mood, visits to GP, self rated health, health complaints, sleep disturbances, all assessed at baseline. †Full model included CIS-fatigue (baseline), CIS-fatigue change score $(\$ 3-t 0)$, CIS-fatigue change score $(+6-10)$, CISactivity (baseline), CIS-activity change score ( $+3-+0)$, CIS-activity change score (t6-t0), MBI-exhaustion (baseline), MBl-exhaustion change score ( $+3-10)$, MBI-exhaustion change score ( $+6-10)$, anxiety (baseline), anxiety change score $(+3-10)$, anxiety change score $(+6-10)$, self rated health (baseline), self rated health change bad to good ( $+0-$ $+3)$, self rated health change good to bad ( $+0-\$ 3)$, self rated health change bad to good $(+3-t 6)$, self rated health change good to bad $(+3-16)$. 
(that is, a higher score at two year assessment compared with the baseline score) also emerged as a significant predictor.

Six baseline predictors of CFS-like caseness versus no fatigue caseness were found: high fatigue, high exhaustion, a low educational level, a self reported visit to the GP because of problems at work, the absence of a self reported visit to the occupational physician (OP), and bad self rated health (table 3). Increases of fatigue and exhaustion in time were found to be significant predictors. A change of self rated health from bad to good between baseline and one year assessment was protective of CFS-like caseness, while a change from good to bad between one and two years of follow up was predictive of CFS-like caseness. When self reported visits to GP and OP at follow up were added to the model, visits to GP and OP at baseline lost significance and a self reported visit to the GP at one year assessment emerged as a predictor.

We found five baseline predictors of non-CFS fatigue caseness compared with no fatigue caseness: high fatigue, low self perceived activity, high exhaustion, high anxious mood, and bad self rated health (table 4). Increases of fatigue and self perceived activity in time and a change of self rated health from bad to good between baseline and one year assessment were found to be significant predictors. In the second step however, exhaustion, and self perceived activity at baseline lost their significance as predictors.

\section{DISCUSSION}

If fatigue can best be understood as a continuum of severity, ${ }^{9}$ it is probable that fatigue among employees and CFS are different but related stages on the continuum. ${ }^{17}$ In addition to this notion, we found that (persistent) unexplained fatigue can be a precursor of a chronic syndrome fatigue-like status. Some $48 \%$ of the 1143 fatigued employees at baseline were (still) fatigue cases 44 months later, and 94 of them ( $8 \%$ of the total group) met the criteria for CFS by that time, none of who had previously received a CFS diagnosis.

As hypothesised, we found that fatigue severity was a strong predictor of fatigue caseness (both CFS-like and nonCFS) four years later almost, despite a limited range in scores at baseline. Work related exhaustion emerged as an important predictor as well, underlining the important contribution of fatigue related factors to the prediction model.

Having a CFS-like status at follow up (compared with both non-CFS fatigue and no fatigue) was strongly associated with a low educational level, with odds ratios ranging from 2.3 to 4.0. In keeping with our hypothesis, having a good self rated health was a strong predictor of the absence of fatigue at follow up as compared with being fatigued (both CFS-like and non-CFS), and the effect increased when changes in self rated health over time were included as predictors.

We found that self reported visits to GPs and occupational physicians emerged as predictors of outcome 44 months later. CFS-like cases were almost twice as likely to report visiting their GP at baseline compared with non-CFS cases (both fatigued and non-fatigued).

The design of the $\mathrm{MCS}^{18}$ offered us the unique opportunity to investigate the development of self reported CFS in a large sample of employees. An obvious limitation and potential source of bias is the use of self report measures. Self report questionnaires clearly have limitations in the assessment of CFS, especially when it comes to somatic conditions that might explain fatigue complaints. However, the CFS criteria we applied are regarded as a good proxy for clinically validated CFS. ${ }^{28}{ }^{29}$ Moreover, our approach enables us to identify CFS-like cases using research criteria free from bias regarding health care seeking or illness recognition by doctors and patients, which is an important advantage of this study. Unfortunately, the full set of CFS criteria was lacking at baseline assessment, and we are not sure whether the selection of potential CFS-like cases at baseline was accurate as we used a provisional set of necessary but insufficient criteria.

In review of our findings, we conclude that severe, persistent, unexplained fatigue can be a precursor of the development of CFS. In understanding the prominent role of self rated health as a predictor of CFS-like caseness and the persistence or recurrence of fatigue, Chalder et al have provided an interesting rationale. They have suggested that a more pessimistic view of the illness may encourage symptom focusing, which in turn may lead to the perpetuation of fatigue. ${ }^{30}$ How other factors play a part in this is yet unknown, but common sense leads us to suggest that the prevention of CFS and the perpetuation of fatigue should in part be aimed at changing the perception of health complaints. Interestingly, such an approach has already shown to be successful in the treatment of CFS. ${ }^{31} 32$

Less clear is the role of self reported visits to the GP or OP as predictor of CFS-like caseness, especially because of the large time delay between exposure and outcome. One explanation might be that visiting a healthcare provider is an indicator of an underlying concept, for example, proneness to focus on health complaints. Hamilton et al concluded that CFS patients consulted their GP more frequently in the 15 years before the development of their condition, possibly because symptoms were perceived more readily as illness or because of an increase in the tendency to consult a doctor. ${ }^{33}$ Afari et al on the other hand have suggested that the probability of receiving a diagnosis of CFS is related to the degree of healthcare access and utilisation. ${ }^{2}$ However, it should be kept in mind that none of the CFS-like cases in this study had received a CFS diagnosis. Interesting in that respect is the fact that most CFS-like cases in this study were men with low education, as compared with most diagnosed CFS patients observed in other studies who are usually professionally successful women. ${ }^{2}$ As most studies of CFS were conducted in clinical settings among healthcare seekers, our dissenting findings might reflect that self selection bias is less of a problem in our study.

The considerations described here suggest several questions. Is health care seeking a differential factor in the persistence of fatigue or the development of a CFS-like status? What are the factors contributing to receiving a diagnosis of CFS? Do sociodemographic factors, access and utilisation of health care, or illness perception have a role in this? And if so, what does it tell us about potential approaches to prevention and treatment? These are important questions for further research.

\section{Authors' affiliations}

M J H Huibers, I J Kant, G M H Swaen, Department of Epidemiology, Maastricht University, Netherlands

J A Knottnerus, M J H Huibers, I Kant, G M H Swaen, Care and Public Health Research Institute (Caphri), Maastricht University

G Bleijenberg, Department of Medical Psychology, UMC St Radboud Nijmegen, Netherlands

S V Kasl, Department of Epidemiology and Public Health, Yale University School of Medicine, New Haven, USA

Funding: this study was funded by the Health Research and Development Council (ZorgOnderzoek Nederland), Netherlands (grant nr. 2830180). The Maastricht cohort study is part of the Netherlands concerted action on "Fatigue at Work" granted by the Netherlands Organisation for Scientific Research (NWO).

Conflicts of interest: none declared.

\section{REFERENCES}

1 Fukuda K, Straus SE, Hickie I, et al. The chronic fatigue syndrome: a comprehensive approach to its definition and study. International Chronic Fatigue Syndrome Study Group. Ann Intern Med 1994;121:953-9. 
2 Afari N, Buchwald D. Chronic fatigue syndrome. Am J Psychiatry 2003;160:221-36.

3 Peterson PK, Schenck CH, Sherman R. Chronic fatigue syndrome in Minnesota. Minn Med 1991;74:21-6.

4 Tirelli U, Marotta G, Improta S, et al. Immunological abnormalities in patients with chronic fatigue syndrome. Scand J Immunol 1994;40:601-8.

5 Wilson A, Hicki I, Lloyd A. Longitudinal study of outcome of chronic fatique syndrome. BMJ 1994;308:756-9.

6 Bombardier $\mathrm{CH}$, Buchwald D. Outcome and prognosis of patients with chronic fatigue vs chronic fatigue syndrome. Arch Intern Med 1995;155:2105-10.

7 Vercoulen JHMM, Swanink CM, Fennis JF, et al. Prognosis in chronic fatigue syndrome: a prospective study on the natural course. J Neurol Neurosurg Psychiatry 1996;60:489-94.

8 Van der Werf SP, De Vree B, Alberts $M$, et al. Natural course and predicting self-reported improvement in patients with chronic fatigue syndrome with a relatively short illness duration. J Psychosom Res 2002;53:749-53.

9 Lewis G, Wessely S. The epidemiology of fatigue: more questions than answers. J Epidemiol Community Health 1992;46:92-7.

10 Bültmann U, Kant IJ, KasI SV, et al. Fatigue and psychological distress in the working population: psychometrics, prevalence and correlates. J Psychosom Res 2002;52:445-52.

11 Janssen N, Kant IJ, Swaen GMH, et al. Fatigue as a predictor of sickness absence: results from the Maastricht cohort study on fatigue at work. Occup Environ Med 2003;60(suppl 1):i71-6.

12 Amelsvoort van LGPM, Kant IJ, Beurskens AJHM, et al. Fatigue as a predictor of work disability. Occup Environ Med 2002;59:712-13.

13 Huibers MJH, Beurskens AJHM, Prins JB, et al. Fatigue, burnout and chronic fatigue syndrome among employees on sick leave: do attributions make the difference? Occup Environ Med 2003;60(suppl 1):i26-31.

14 Wessely S, Chalder T, Hirsch S, et al. Postinfectious fatigue: prospective cohort study in primary care. Lancet 1995;345:1333-8.

15 Taylor RR, Jason LA, Curie CJ. Prognosis of chronic fatigue in a communitybased sample. Psychosom Med 2002;64:319-27.

16 Skapinakis P, Lewis G, Mavreas V. One-year outcome of unexplained fatigue syndromes in primary care: results from an international study. Psychol Med 2003;33:857-66

17 Huibers MJH, Bleijenberg G, Amelsvoort van L, et al. Predictors of outcome in fatigued employees on sick leave: results from a randomized trial. J Psychosom Res (in press).

18 Kant IJ, Bültmann U, Schroer CAP, et al. An epidemiological approach to study fatigue in the working population: The Maastricht Cohort Study. Occup Environ Med 2003;60(suppl 1):i32-9.
19 Vercoulen JHMM Swanink CM, Fennis JF, et al. Dimensional assessment of chronic fatigue syndrome. J Psychosom Res 1994;38:383-92.

20 Beurskens AJHM, Bültmann U, Kant IJ, et al. Fatigue among working people: validity of a questionnaire measure. Occup Environ Med 2000:57:353-7.

21 Vercoulen JHMM, Alberts M, Bleijenberg G. De Checklist Individual Strength (CIS). Gedragstherapie 1999;32:31-6.

22 Schaufeli WB, Leiter MP, Maslach C, et al. The Maslach Burnout InventoryGeneral Survey. In: Maslach C, Jackson SE, eds. Maslach Burnout Inventory Manual. Palo Alto, CA: Consulting Psychologists Press, 1996.

23 Sluiter JK, Van der Beek AJ, Frings-Dresen MHW. The influence of work characteristics on the need for recovery and experienced health: a study on coach drivers. Ergonomics 1999:42:573-83.

24 Jansen NWH, Kant IJ, Van den Brandt PA. Need for recovery in the working population: descriptions and associations with fatigue and psychological distress. Int J Behav Med 2002;9:322-40.

25 Goldberg DP, Williams P. The user's guide to the General Health Questionnaire. Windsor: NFER-Neslon, 1991.

26 Ware JE Jr, Sherbourne CD. The MOS 36-item short-form health survey (SF36). I. Conceptual framework and item selection. Med Care 1992;30:473-83.

27 Aaronson NK, Muller M, Cohen PD, et al. Translation, validation, and norming of the Dutch language version of the SF-36 Health Survery in community and chronic disease populations. J Clin Epidemiol 1998;51:1055-68.

28 Taylor RR, Jason LA, Torres A. Fatigue rating scales: an empirical comparison. Psychol Med 2000;30:849-56.

29 Jason LA, Taylor RR. Applying cluster analysis to define a typology of chronic fatigue syndrome in a medically-evaluated, random community sample. Psychol Health 2002; 17:323-37.

30 Chalder T, Godfrey E, Ridsdale L, et al. Predictors of outcome in a fatigued population in primary care following a randomized controlled trial. Psychol Med 2003;33:283-7

31 Prins JB, Bleijenberg G, Bazelmans E, et al. Cognitive behaviour therapy for chronic fatigue syndrome: a multicentre randomised controlled trial. Lancet 2001;357:841-7.

32 Whiting $\mathrm{P}$, Bagnall $\mathrm{AM}$, Sowden $\mathrm{AJ}$, et al. Interventions for the treatment and management of chronic fatigue syndrome: a systematic review. JAMA $2001 ; 286: 1360-8$

33 Hamilton WT, Hall GH, Round AP. Frequency of attendance in general practice and symptoms before development of chronic fatigue syndrome: a case-control study. Br J Gen Pract 2001;51:553-8. 